\title{
Efeito da Lactoferrina Na Resistência de Lactobacillus Casei Adicionados em Flan de Chocolate e Submetido a Condições Simuladas do Trato Gastrointestinal Humano
}

\author{
Angélica Basso Kimura (I), Kawanna Cristina de Lima (I), Fernanda \\ Diekmann Mantovani (I), Cínthia Hoch Batista de Souza (I), Elsa \\ Helena Walter de Santana (I), Lina Casale Aragon-Alegro (I)
}

(I) UNOPAR - Universidade Norte do Paraná (Av. Paris, 675, Jd Piza)

\section{Resumo}

Nos últimos anos, as indústrias lácteas têm se preocupado com o desenvolvimento de produtos contendo probióticos e que apresentem longa vida-de-prateleira. Embora vários estudos avaliando-se a influência da lactoferrina (Lf) sobre microrganismos probióticos tenham sido conduzidos, há poucos dados científicos sobre esta ação em alimentos lácteos. Assim, o objetivo deste trabalho foi avaliar a ação da lactoferrina sobre a multiplicação de Lactobacillus casei em flan de chocolate, além de avaliar a sobrevivência do microrganismo probiótico durante a exposição do produto a condições de simulação do trato gastrointestinal. Para isso foram produzidos um flan com adição de lactoferrina e um sem a adição desta proteína, ambos sabor chocolate e adicionados de Lactobacillus casei. A enumeração do microrganismo adicionado e análise do $\mathrm{pH}$ foram realizadas após 1, 7, 14 e 21 dias de armazenamento, e a composição centesimal dos flans, no sétimo dia após a produção dos mesmos. A avaliação da resistência da cultura probiótica às condições do trato gastrointestinal foi feita empregando-se um modelo in vitro, utilizando-se sucos gástricos e entéricos simulados, bem como enzimas do trato gastrintestinal. Todo experimento foi repetido 3 vezes. Os dados foram avaliados através de análise de variância (ANOVA) e teste de Tukey, 
utilizando o programa Statistica. L. casei manteve-se viável e em populações acima de $6 \log \mathrm{UFC} / g$ nos dois produtos avaliados, não tendo sido verificada diferença entre as duas formulações de flan. Quando submetido à simulação das condições gástricas, a população de L. casei nos diferentes produtos apresentou redução de 4 ciclos logarítmicos. L. casei adicionado no flan sem adição de lactoferrina apresentou uma recuperação de aproximadamente 2 ciclos logarítmicos durante a simulação entérica, demonstrando que a Lf não deve ser uma substância de escolha para adição neste tipo de produto probiótico.

Palavras-Chave: leite, compostos bioativos, probióticos, sobremesa Agência de Fomento: Funadesp 